\title{
Exploration of Conceptual Understanding and Science Process Skills: A Basis for Differentiated Science Inquiry Curriculum Model
}

\author{
Jigger P. Leonor
}

\begin{abstract}
This qualitative study explores the students' conceptual understanding and science process skills through differentiated science inquiry leading to a differentiated science inquiry curriculum model. Through phenomenographic analysis and in-depth interview, the conceptual understanding of students as based on SOLO (Structure of Observed Learning Outcome) Taxonomy Model and DOK (Depth of Knowledge) Levels in Science revealed that as they engaged in DSI activities, they were able to exhibit their conceptual understanding characterized by integrating the different aspects of a concept into a coherent whole and extending it to making connections not only within the given subject area, but also beyond it. They were able to conceptualize at a higher level of abstraction and look at ideas in new and different ways. They showed recall of information, made some decisions on how to approach the problem, displayed deep knowledge using reasoning, planning, evidence and selected or devised one approach among many alternatives on how the situation can be solved. Chemistry concepts were strengthened and understood from their basic to complex tenets. These results led the students to achieve a range of accelerated progression as indicated by a positive transition from their prior understanding to a new conceptual improvement. By means of methodological triangulation, the science process skills of students were fully displayed, practiced, and applied as they engaged in higher levels of inquiry thereby directing them to a progressive manifestation of the basic and integrated science process skills.
\end{abstract}

Index Terms-Differentiated science inquiry, conceptual understanding, science process skills, curriculum model, chemistry concepts.

\section{INTRODUCTION}

The evolution in science and technology forces science education to develop and reorganize itself in terms of perception and method of approach, which leads pedagogy experts to think about the concept of knowledge and how it should be conducted. This is due to the fact that new concepts, understandings, and phenomena in science require a new approach or a re-evaluation of the old approach, all for the goal of passing to the learner the scientific knowledge and process skills.

Similarly in today's increasingly diverse classrooms, teachers are expected to address a whirlwind of initiatives to cater to the greater diversity of needs than ever before [1] observed that no two students enter a classroom with identical abilities, experiences, and needs. Learning style,

Manuscript received February 12, 2014; revised May 12, 2014.

Jigger P. Leonor is with University of St. La Salle, Philippines (e-mail: jiggerleonor@yahoo.com). language proficiency, background knowledge, readiness to learn, and other factors can vary widely within a single class group. Regardless of their individual differences, however, students are expected to master the same concepts, principles, and skills. So what lies ahead?

Differentiated instruction is one of the best possible answers to this reality in the classroom. Based on this theory, teachers can structure learning environments that will address the variety of learning styles, interests, and abilities exhibited by the students.It is based upon the belief that students learn best when they make connections between the curriculum and their diverse interests and experiences, thus greatest learning occurs when students are pushed slightly beyond the point where they can work without assistance [1].

Differentiation consists of the efforts of teachers to respond to variance among learners in the classroom Whenever a teacher reaches out to an individual or small group to vary his or her teaching in order to create the best learning experience possible, that teacher is differentiating instruction [2]

We are constantly confronted by 21 st century learners who are inquisitive, critical and with definite goals in mind. They know how to incorporate logical reasoning when solving problems. They think about their thinking and know the whys behind their actions. These learners are also innovators and creators [3].

In conducting this study, the researcher has considered that the high school students in the USLS-IS must strengthen their conceptual knowledge in science, while seeing the need to identify and develop their science process skills. Ref. [4] pointed out that science process skills are inseparable in practice from the conceptual understanding and should be discussed and identified because of their central role in learning with understanding, whether in formal education or throughout life.

These proofs and expert convictions lead the researcher to the main focus of this study which is to infuse differentiated inquiry-based instruction applied to high school science curriculum as an enduring understanding, as well as pedagogy for science teaching to further develop students' conceptual understanding and process skills in the sciences.

As a challenge to educational leaders who desire to meet a range of students' learning needs and who are driven to implement pedagogical practices responsive to the challenges of increasing student diversity and academic accountability, this study may serve as a basis for the curriculum model which could address the aforementioned predicament. 


\section{Methodology}

This study made use of qualitative method involving phenomenographic analysis in dealing with conceptual understanding in chemistry.

Marton (1986) described phenomenography as an empirically based approach that aims to identify the qualitatively different ways in which different people experience, conceptualize., perceive, and understand various kinds of phenomena [5].

The SOLO Taxonomy Model and DOK Levels in Science were used as bases on how students exhibit conceptual understanding in chemistry as reflected in the conceptual test and supplemented by an in-depth interview.

Methodological triangulation, which involves the convergence of data from multiple data collection sources, utilizing self-assessment of Science Process Skills Inventory (SPSI), Direct Observation, Document Analysis and Actual Performance Task Assessment (APTA) with in-depth probing interview indicated the science process skills of high school students in chemistry.

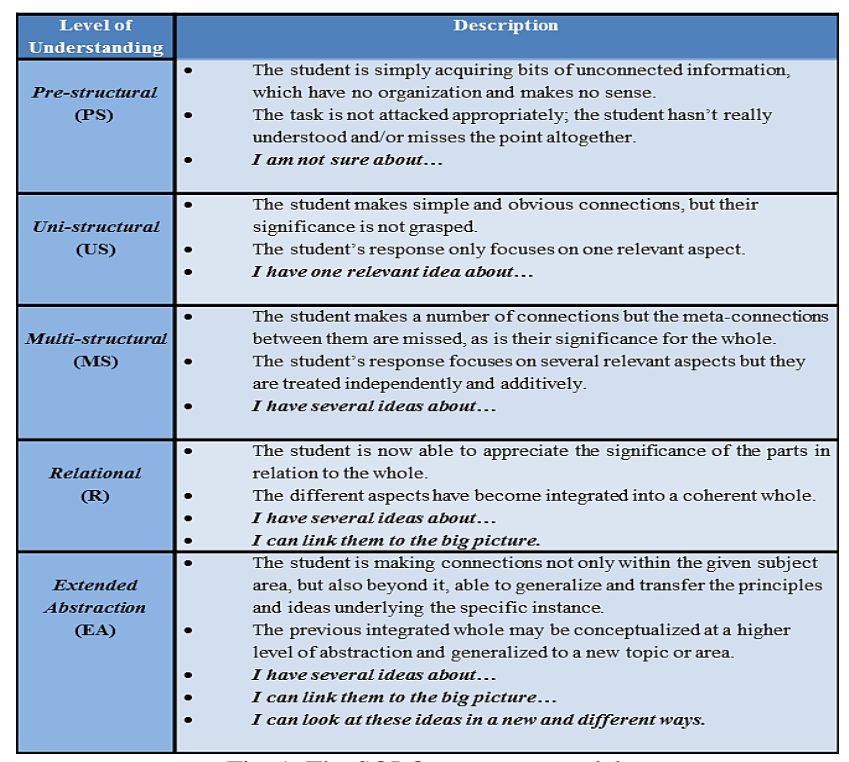

Fig. 1. The SOLO taxonomy model.

\begin{tabular}{|c|c|c|c|}
\hline $\begin{array}{c}\text { Extent of } \\
\text { Progression }\end{array}$ & $\begin{array}{c}\text { Level of } \\
\text { Understanding }\end{array}$ & Level of Thinking & Description \\
\hline & PS $\rightarrow$ US & PC $\rightarrow$ RR & Fairly accelerated \\
progression & RS $\rightarrow$ MS & R $\rightarrow$ SC \\
+1 & MS $\rightarrow$ R & SC $\rightarrow$ ST \\
& RT $\rightarrow$ EA & ST $\rightarrow$ ET & \\
\hline & PS $\rightarrow$ MS & PC $\rightarrow$ SC & Moderately accelerated \\
progression
\end{tabular}

Fig. 2. The extent of progression and regression in the level of understanding and thinking.

In order to determine the extent of progression and regression of students' level of understanding and thinking
Fig. 2 was used. The graphical representation is supplemented by Fig. 3 .

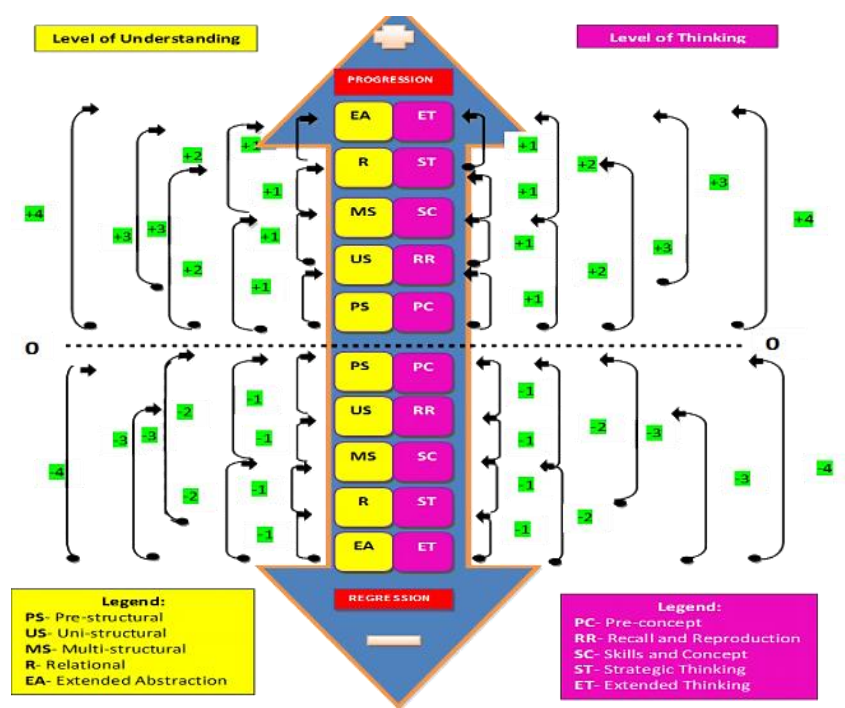

Fig. 3. Graphical representation of the extent of progression and regression in the level of understanding and thinking.

The degree of progression for Science Process Skills was determined through the difference between their pre-self-assessment and post self-assessment through SPSI results. The degree of progression for APTA was determined through the difference between their APTA results during andafter. The value of progression was based on the number of intervals between the extent of SPS as reflected from SPSI and APTA.The extent of science process skills was determined through Fig. 4 below.

\section{RESULTS AND DISCUSSION}

\section{A. On the Extent of Level of Understanding and Thinking}

The tables and figures display the level of understanding and thinking of participants on the post-conceptual question 1 on density. Each represents a participant from the four levels of science inquiry that were differentiated. The question is:

"If you had an enormous piece of wax as big as the size of a house, do you think it would float or sink if it was placed in water like in a lake or huge swimming pool? Explain the reasons for your answer."

If $2 \mathrm{had}$ an enormous price of wax the sizi of a house, 2 thene It would float if it was placed in water like in a lake on a huge unimining pooe due to buoyancy. Buoyancy is the power of a liquid to push an upward force upon an objict. that's why boat made of steer or metal float not sinke. I think the wax has lesser density than one or it is leseer in density compared to that of the water

Fig. 4. Esther's answer to question 1 of the post-conceptual test on density in a confirmatory inquiry.

Esther indicated a new reason concerning the floating of the wax. She attributed it to the concept of "buoyancy" by citing its definition and supporting it with direct evidence stating why boat made up of steel or metal float on seawater. 
Nevertheless, she further supports it by "density" as another factor related to the situation. Accordingly, she is showing a Relational and Strategic Thinking as displayed in Fig. 5-Fig. 10.

Luke substantiated the aforementioned responses through recalling a previous experiment which led him to conclude that "heavier things float." The shape of the object may also affect the density, thus floating or sinking may happen. However, there is an indirect association of mass to volume. He only emphasized that if the house is massive, then it will sink. So accordingly, this answer is designated as Multi-structural and Recall and Reproduction.

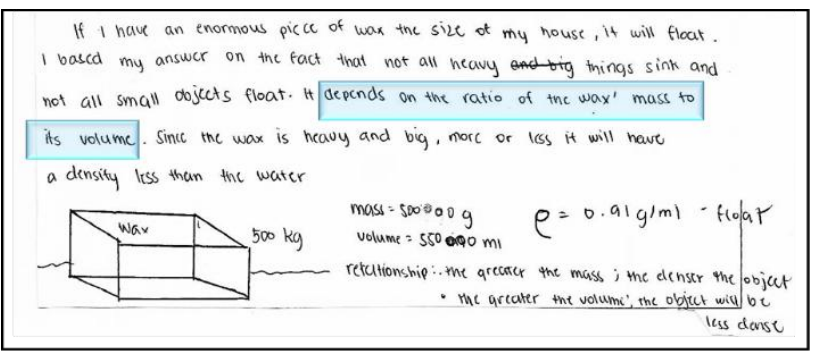

Fig. 5. Matthew's answer to question 1 of the post-conceptual test on density in a guided inquiry.

The post-conceptual answer of Matthew to question 1 on density exposes a complete link among the variables - mass, volume and how they are related to density. He emphasized that the ability of a substance to float or sink is related to the ratio of mass and volume. Eventhough an enormous wax appears heavy, its density is less than the water causing it to float. Hence, his answer is classified as Relational and correspondingly belongs to Strategic Thinking.

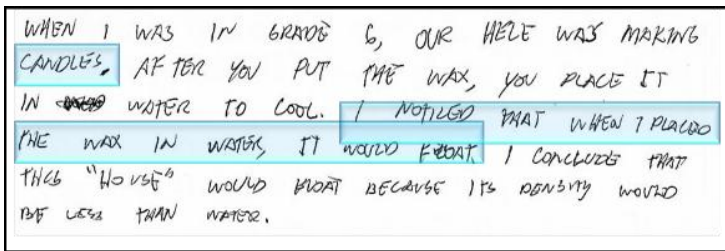

Fig. 6. Daniel's answer to question 1 of the post-conceptual test on density in a self-directed inquiry.

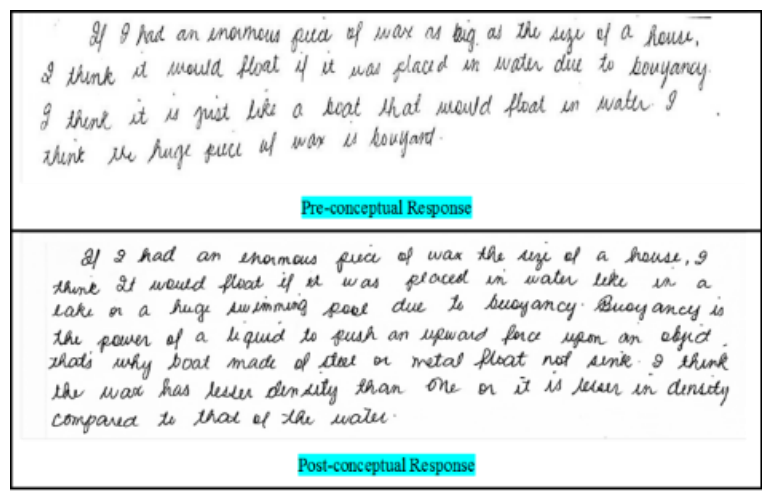

Fig. 7. Esther's answer to question 1 of the pre-post conceptual test on density in a confirmatory inquiry.

Daniel cited his Grade 6 HELE class while they were making candles. He observed that the candle which is covertly made up of wax when placed on water floats as taken from his response stating "I noticed that when I placed the wax in water, it would float." At the same time, a house which is made up of wax will likewise float since it has a lesser density than water. Inasmuch as the level of understanding is concerned, this answer is classified as Extended Abstraction and Extended Thinking.

\section{B. On the Extent of Progression on the Level of Understanding and Thinking}

The next section displays the extent of progression in the students' level of understanding and thinking.

Esther exhibited +2 which is characterized by moderately accelerated progression in her level of understanding and level of thinking as indicated by a transition from Uni-structural to Relational level of understanding and from Recall and Reproduction to Strategic thinking level.

In her pretest, she credited the floating of the wax to the concept of buoyancy and associated it with the boat floating on water. Buoyancy is the main reason why the wax floats. She further supports the concept by citing a boat that floats on water because it is buoyant. Going back to the wax, it floats because it is likewise buoyant. In the posttest, still she focused her explanation to the concept of buoyancy. She additionally defined it as an upward force exerted upon an object as applied to the floating of a boat though it is made up of metal. Moreover, she credited the floating of the wax to the concept of density. Since the density of the wax is less than the water, the wax will float.

Luke manifested +1 signifying a fairly accelerated progression in the level of understanding and thinking. $\mathrm{He}$ possessed a transition from Uni-structural to Multi-structural level of understanding and from Pre-structural to Recall and Reproduction level of thinking. In his pre-conceptual response produced an incorrect answer to the question. He has an overt confusion of the concept of density as applied in sinking and floating. He reasoned that the piece of wax will sink since its density is lower and heavier than water. He failed to relate object's density to its mass. Heavier mass and lesser density is attributed to sinking.

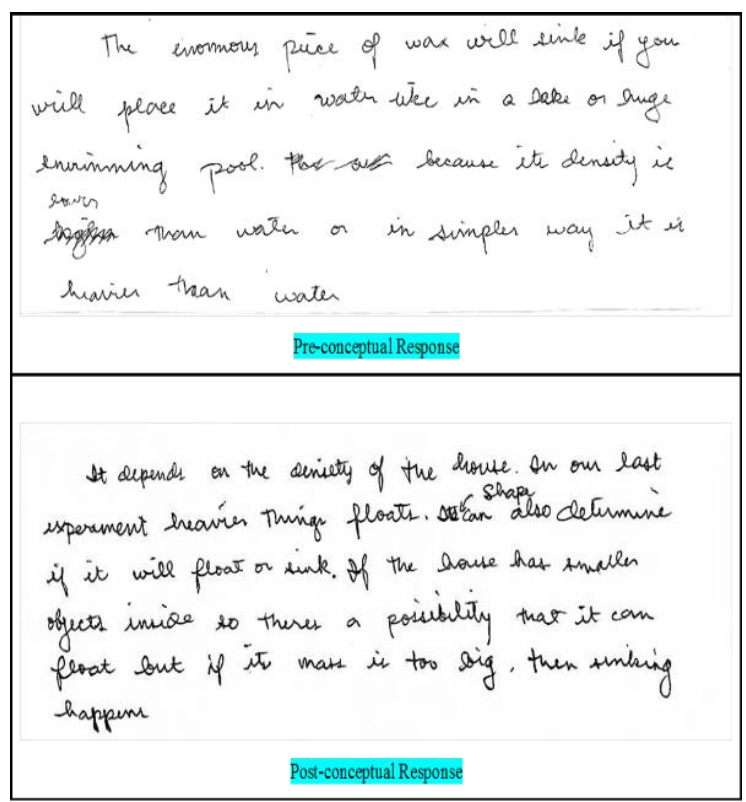

Fig. 8. Luke's answer to question 1 of the pre-post conceptual test on density in structured inquiry.

Paul possessed the highest progression in the group with +3 in his level of understanding and +4 signifying an extremely accelerated progression characterized by a 
transition from Pre-concept to Extended thinking. Stephen exhibited a +2 level of understanding and +3 in his thinking.Based from Paul's pre-conceptual response, he exculpated a correct answer. He associated the phenomenon of floating to an ice submerged in water. He failed to mention mass, volume or density and missed to relate it to floating and sinking of an enormous piece of wax. His prior idea on ice floating in water led him to predict the possible occurrence of the wax as size of the house.

His new explanation reveals an association of the phenomenon with regard to the composition of an object giving emphasis on density as a definite property of matter. Regardless of its mass and volume, since wax has the same density which is less than the water, so it will definitely float. He cited a candle which floats on water and related it to a big house made of wax which will float on water still. A practical explanation was given by Paul. He made a consistent comparison from his prior experience to the given situation and condition. A concept of "generalization" is apparent in his response.

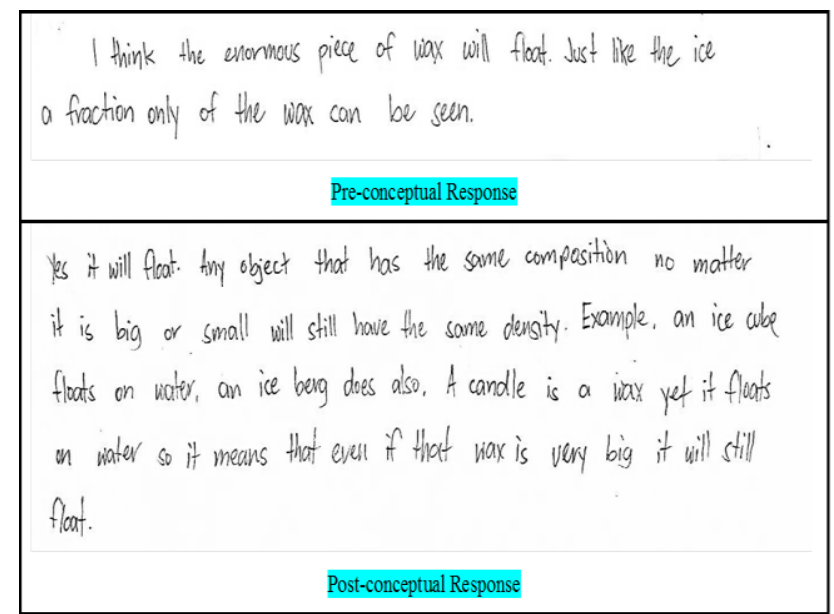

Fig. 9. Paul's answer to question 1 of the pre-post conceptual test on density in guided inquiry.

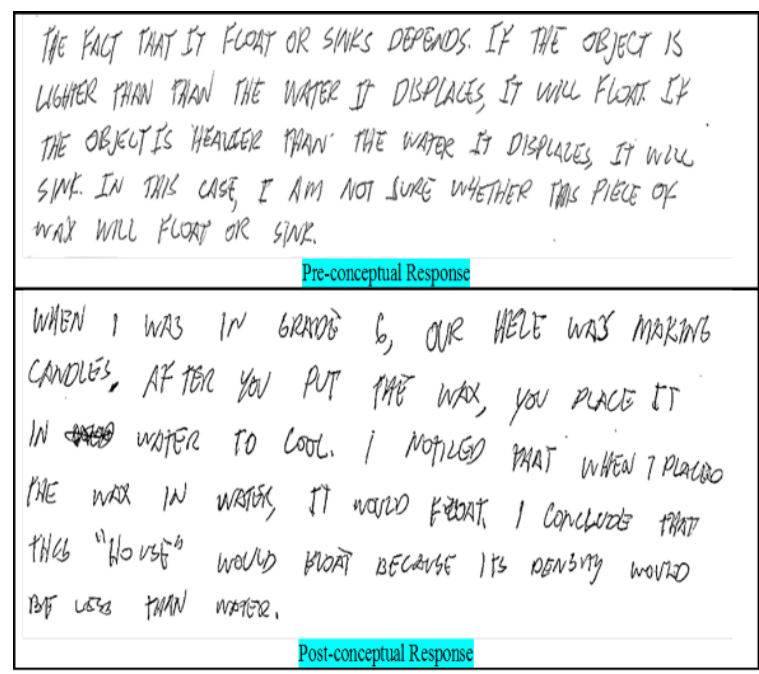

Fig. 10. Daniel's answer to question 1 of the pre-post conceptual Test on density in self-directed inquiry.

Daniel achieved a +2 which connotes a moderately accelerated progression characterized by a transition from Multi-structural to Extended Abstraction level of understanding and from Skills and Concept to Extended thinking.
In the case of Daniel, he couldn't decide if the wax will sink or float. For him, floating and sinking depends on the mass of the object and the amount of water it displaces. He has a concept of mass and volume, yet failed to relate them as an integrated whole. In his post-conceptual response, he associated the phenomenon based from his previous experience when they were making candles. He observed that the candle which is apparently made up of wax when placed on water floats. Applied to the situation, since the wax is made up of a wax, it will likewise float no matter how heavy it appears simply because it has a lesser density than water.

\section{On the Progression in the Science Process Skills}

Fig. 10 presents the summary of the frequency and percentage of progression in the extent of SPS based on SPSI and APTA. On the basis of SPSI, most of the participants is rated an A remark indicating about the right progression in the skills of questioning, predicting, planning an experimenting, measuring, and interpreting. Most of them have an A- remark in classifying skill signifying too little progression. Looking at their APTA results, most of the participants achieved about a right progression in the skills of observing, questioning, hypothesizing, predicting, planning and experimenting, measuring, interpreting, drawing conclusion, and communicating. In the skills of classifying and controlling variables they showed too little progression as indicated by an A- remark.

It is deduced from the findings that there must be a need to cater on the skills of classifying and controlling variables as consistent skills which showed a little progression. High school students were observed to fail in classifying substances based on the similarities and differences in properties. As part of conducting a scientific investigation, they found to have less emphasis on controlling variables which in turn lowered the frequency as reflected from the figure.

\section{CONCLUSIONS}

As high school students engaged in DSI activities, they were able to exhibit their conceptual understanding characterized by integrating the different aspects of a concept into a coherent whole and extending it to making connections not only within the given subject area, but also beyond it. They were able to conceptualize at a higher level of abstraction and looked at ideas in new and different ways. Furthermore, they showed recall of information, made some decisions on how to approach the problem, displayed deep knowledge using reasoning, planning, evidence and selected or devised one approach among many alternatives on how the situation can be solved. Chemistry concepts were strengthened and understood from its basic to complex tenets. These results led the students to achieve a range of accelerated progression as indicated by a positive transition from their prior understanding to a new conceptual improvement.

The science process skills were fully displayed, practiced, and applied by the high school students as they engaged in higher levels of inquiry thereby directing them to a progressive manifestation of the basic and integrated science 
process skills.

\section{ACKNOWLEDGMENTS}

The researcher would like to acknowledge the support extended by the University of St. La Salle-Integrated School Administrators, teachers and students.

\section{REFERENCES}

[1] J. Willoughby. (2005). Differentiating instruction: meeting students where they are. [Online]. Availanle: http://www.glencoe.com

[2] C. A. Tomlinson and M. Imbeau, Leading and managing a differentiated classroom, United States of America: ASCD Publications, 2010.

[3] W. Conklin, Higher order thinking skills to develop 21st century learners, California, United States of America: Shell Education Publishing Inc., 2012.
[4] W. Harlen. (2010). Purposes and procedures for assessing science process skills. Assessment in Education: Principles, Policy \& Practice [Online]. Availanle: http://www.tandfonline.com

[5] J. Richardson, "The Concepts and Methods of Phenomenographic Research Review of Educational Research Spring," vol. 69, no. 1, pp. 53-82, 1999 .

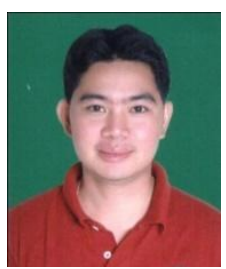

Jigger P. Leonor graduated his masters in education in chemistry at the University of San Agustin Iloilo City, Philippines and his doctor of philosophy in educational management at the University of St. La Salle, Bacolod City, Philippines. He is teaching chemistry and biology for the past 10 years and authored a book entitled Conceptual Science and Beyond for High school grade 8, 9, and 10 students. He has been a research consultant and a local and international research presenter. His research interest is in line with science education research. Currently, he is connected at the University of St. La Salle-Bacolod City, Philippines teaching high school, college and graduate school students 